\title{
REALISED GENETIC GAINS AND ESTIMATED GENETIC PARAMETERS OF TWO EUCALYPTUS GRANDIS X EUCALYPTUS UROPHYLLA HYBRID BREEDING STRATEGIES
}

Gert $\mathrm{J}$ van den Berg ${ }^{1,3}$, Steven D Verryn ${ }^{2,3}$, Paxie W Chirwa $^{3}$ and Francois van Deventer ${ }^{1}$

\author{
${ }^{1}$ Mondi Forests (Pty) Ltd, Hilton, South Africa \\ ${ }^{2}$ Creation Breeding Innovations cc, Pretoria, South Africa \\ ${ }^{3}$ Faculty of Natural and Agricultural Sciences, University of Pretoria, Pretoria, South Africa \\ Corresponding author, email: gert.vandenberg@mondigroup.co.za
}

\section{Abstract}

Conventionally, Eucalyptus grandis $x$ E. urophylla (GU) hybrid material has first been tested as seedlings in progeny trials for at least four years before ortets were selected and ramets of the selected ortets were propagated to test in clonal trials. The primary constraint with this "conventional hybrid breeding strategy" (CHBS) is the time required to first test the hybrid material as seedlings. In order to address this, an "accelerated hybrid breeding strategy" (AHBS) was investigated to reduce the time spend on testing GU hybrid material as seedlings. However, it is of utmost importance to quantify the impact the AHBS might have on genetic gains and genetic information. With this in mind, two clonal populations have been established with genetic material that derived from the CHBS and the AHBS. The main purpose of this study is therefore to do a comparative study between the CHBS and AHBS to firstly quantify the genetic gains per unit time for GU hybrid clonal populations that have been derived from the CHBS and AHBS respectively; and secondly to obtain 
genetic parameters such as heritabilities, the ratio of dominance, clonal within family variance and the proportion of additive and non-additive genetic variance.

The results of our study indicated that the percentage realised volume gains per year was higher for the AHBS (3.7\%) than for the CHBS (1.9\%) when compared to the GU commercial clone. Thus, shortening the testing time of GU seedlings had a positive impact on volume gains per year. With regards to genetic parameters, both the AHBS and CHBS clonal populations indicated that non-additive genetic variation explained majority ( $88 \%$ and $71 \%$ respectively) of the genetic variation. Due to the pre-eminence of non-additive genetic variation, the narrow sense heritabilties for the female and male effects were negligible for both clonal populations. Overall, the majority of the non-additive genetic variation was explained by the proportion of dominance variance, and less by the clone within family effect. These results suggest that: firstly the time spend on testing GU hybrid material as seedlings should be minimised; and secondly a hybrid breeding strategy to capture non-additive genetic variation should be adopted.

\section{Keywords}

Eucalyptus grandis x E. urophylla clonal populations; hybrid breeding strategies; genetic parameters; realised genetic gains.

\section{Introduction}

Eucalypts have the ability for inter-specific hybridisation (Griffin et al. 1988; Potts and Wiltshire 1997). Its hybrids hold the potential to produce genotypes with special combinations, e.g. specific timber properties, disease resistance and greater vigour 
compared to the pure species (Hettasch et al. 2002). Hybrids with Eucalyptus grandis are important in countries such as Brazil, China, Colombia, Congo, South Africa and Venezuela (Denison and Kietzka 1992; Endo and Lambeth 1992; Nikles 1992; Ferreira and Santos, 1997; Wright 1997; de Assis 2000; Retief and Clarke 2000; Verryn 2000). Its hybrids with various species, especially Eucalyptus urophylla, are becoming increasingly important for enhancing yields and disease resistance (White et al. 2007). A good example of where E. grandis can't be planted as a pure species due to its susceptibility to fungal diseases, but are grown successfully as a hybrid partner with E. urophylla is in the sub-tropical coastal region of South Africa, namely Zululand (Retief and Stanger 2009). Superior clones for pulp production in Zululand have been obtained from this inter-specific hybrid population and have produced volume gains of up to $50 \%$ over the $E$. grandis seedling controls (Gardner 2001). However, a primary constraint in the management of hybrid breeding when compared to pure species breeding, is the additional time required to test the hybrid material. With the CHBS, GU hybrid material is first tested as seedlings in progeny trials across sites for at least four years. Ortets are then selected and ramets of the selected ortets are thereafter propagated to test in clonal trials. The feasibility of testing GU hybrid material as seedlings to such an extent is questionable considering the weak phenotypic correlation that was detected between ortets and ramets (Van den Berg et al. 2016). In addition, genetic gains also need to be achieved as rapidly as possible in order to justify expenditures associated with tree improvement. This has led to the concept of maximizing genetic gains per unit time instead of per cycle of breeding (White et al. 2007). With this in mind, an AHBS was developed and tested in order to reduce the time and money spent on testing GU hybrid material as seedlings. The impact of the AHBS on realised genetic gains 
needs to be quantified in order to justify the implementation of this strategy. Realised gains are obtained by comparing unimproved varieties to improved varieties (or with varieties having varying levels of improvement) in the same experiment (Zobel and Talbart 1984; White et al. 2007). In this study, five controls at various levels of improvement were used in all the experiments. In addition, genetic parameters such as heritabilities and the proportion of additive and non-additive genetic variance of both the GU clonal populations need to be determined in order to design the best inter-specific hybrid breeding strategy. A comparative study between the CHBS and the AHBS was therefore conducted with the following objectives:

- Obtain genetic parameters for GU hybrid clonal populations that were derived from the CHBS and AHBS.

- Quantify the realised genetic gains per unit time for the GU clones that were generated from the CHBS and AHBS.

\section{Materials and methods}

\section{Hybrid breeding strategies}

The breeding strategy preceding the production of GU hybrid seed was the same for the CHBS and AHBS. All the parents were selected based on their mature age phenotypes for growth and tree form. The E. grandis parents are cloned selections made in a second generation progeny trial series from the South Africa Forestry Research Institute programme. The E. urophylla parents are cloned selections from an unimproved provenance/progeny trial series of open-pollinated seed collected from different provenances on Indonesian Islands. The selected E. grandis and the E. urophylla parents were established in an elite potted orchard where controlled 
pollinations commenced. The controlled pollinations between the $E$. grandis and $E$. urophylla parents were mainly driven by flowering. Full-sib GU hybrid families from the first two controlled pollination seasons were assigned to the CHBS and thereafter to the AHBS.

The main difference between the CHBS and AHBS lies in the screening of GU seedlings as the first phase of testing hybrid material (Figure 1).

In the CHBS, GU hybrid seedlings were tested in a series of progeny trials across 7 sites. These trials were established at the recommended commercial spacing $(3 \mathrm{~m} \mathrm{x}$ $2 m)$. Each GU hybrid family was planted in a $1 \times 6$ tree line plot and replicated between 6 and 12 times across each site. Tree growth was measured when the trees were 4 years of age, and the best performing families and individuals within families were then assessed for pest and disease resistance as well as tree form. Growth results of these GU hybrid progeny trials were described by Van den Berg et al. (2016). Based on the 4 year results, best individuals were then selected and used to produce cuttings for clonal testing.

In the AHBS, the GU seedlings were tested over a shorter time period and at a minimum cost. The GU hybrid seedlings were planted in a "hybrid seedling selection block" (HSSB). Each GU family was planted in a single plot of $10 \times 10$ trees at a single site. The site was selected at the nursery in order to reduce costs associated with establishing field trials at various sites away from the nursery. The seedlings were planted at a narrow spacing of $1 \mathrm{~m} \times 1 \mathrm{~m}$ in order to minimize the space used for testing, as well as to force earlier onset of competition. At 1.5 years of age, the best individuals within each family were selected based on growth and resistance to pests and diseases. No measurements were taken at this stage and all selections were done visually in order to save costs. Cuttings were then produced from the 
Figure 1: Timelines and procedures for the conventional and accelerated hybrid breeding strategies.

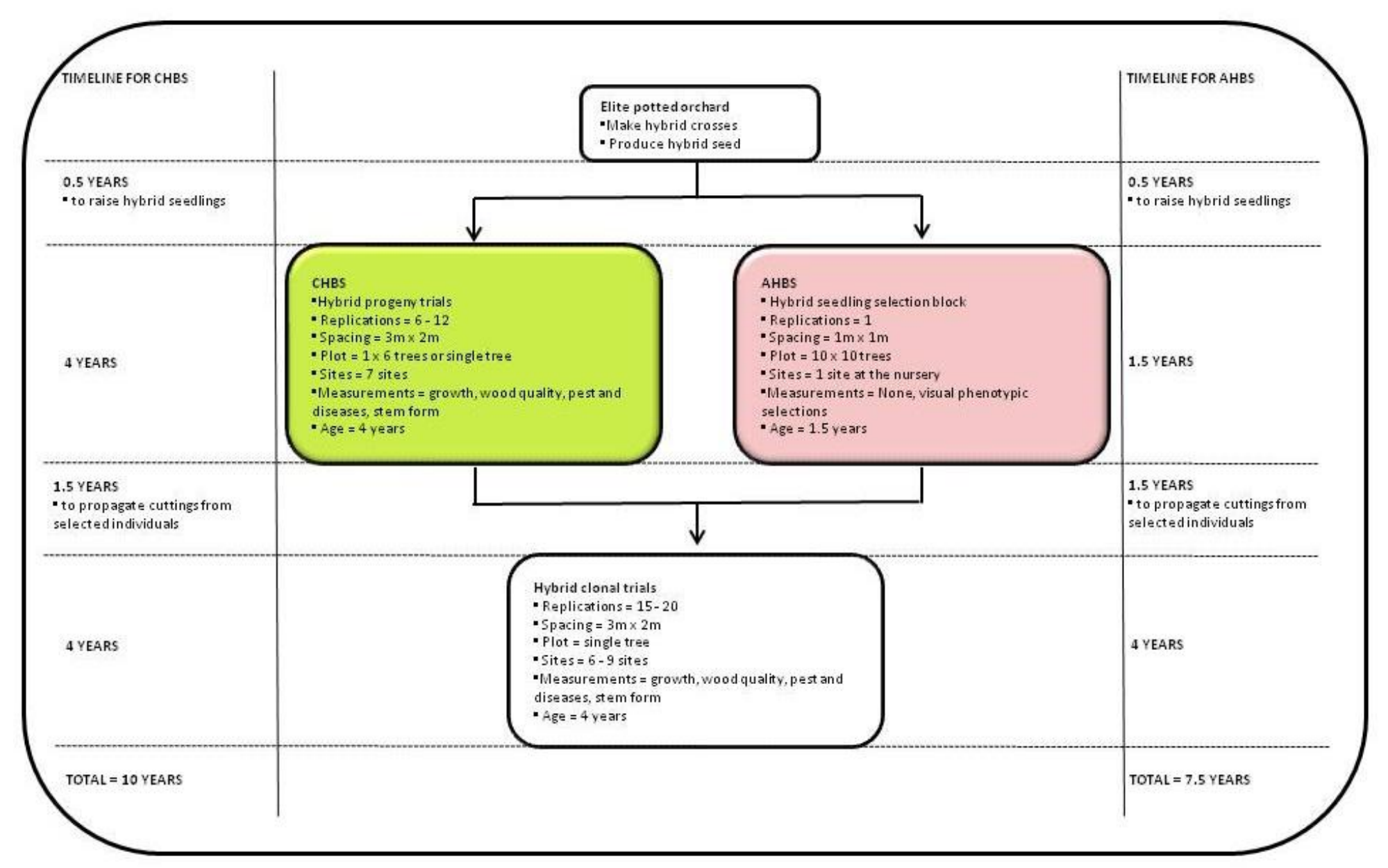


selected ortets and tested in clonal trials. The main purpose of the AHBS is to investigate what the impact will be on clonal performance if the screening of GU hybrid seedlings is done more cost effectively and over a shorter time period. With this in mind, the clones derived from both strategies were tested in clonal trials with the same design, as described in Table 2.

\section{Breeding material}

The clonal population of the CHBS consists of 148 selections (Table 1) that derived from a series of GU seedling progeny trials described by Van den Berg et al. (2016). A total of 24 E. grandis and 23 E. urophylla selected parents were used in various combinations to produce $108 \mathrm{GU}$ families for the progeny trials. The fundamental Hardy-Weinberg assumption that crosses are made from parents selected randomly from the population of interest, has therefore been violated. The $148 \mathrm{GU}$ ortets selections were made from 63 families in the progeny trials. This equates to a selection intensity of $58 \%$ (63 from 108 families) at the family level and $2 \%$ (148 from 6840 individuals) at the population level. All ortets were selected between 4 and 7 years of age for growth, pest and disease resistance as well as tree form. Between 90 and 180 ramets were produced from each ortet and were established in a series of clonal trials at a minimum of 6 sites.

The clonal population of the AHBS consists of 211 selections (Table 1) from $38 \mathrm{GU}$ families in the HSSB. A total of $11 \mathrm{E}$. grandis and $18 \mathrm{E}$. urophylla parents were used to produce the $38 \mathrm{GU}$ families (Table 1). Individual selections were made from all 38 families. All ortets were visually selected at 1.5 years of age for growth and pest and disease resistance. The selection intensity for the population was $5.5 \%$ (211 from 
Table 1: Number of selections made from each $E$. grandis $x$. urophylla full-sib hybrid family and the number of clonal trials established for the conventional and accelerated hybrid breeding strategies.

\begin{tabular}{|c|c|c|c|c|c|}
\hline \multicolumn{3}{|c|}{ Clonal material of conventional hybrid breeding strategy } & \multicolumn{3}{|c|}{ Clonal material of accelerated hybrid breeding strategy } \\
\hline Fam & Selections & Trials & Fam & Selections & Trials \\
\hline G1xU12 & 1 & 6 & G12xU28 & 5 & 9 \\
\hline G3xU17 & 3 & 6 & G12xU29 & 4 & 9 \\
\hline G3xU19 & 1 & 6 & G12xU38 & 4 & 9 \\
\hline G4xU3 & 3 & 6 & $\mathrm{G} 12 \times \mathrm{U} 40$ & 3 & 9 \\
\hline G4xU6 & 1 & 6 & G12xU42 & 1 & 9 \\
\hline G4xU8 & 9 & 6 & G13xU39 & 13 & 9 \\
\hline G4xU12 & 4 & 6 & G14xU2 & 1 & 9 \\
\hline G4xU16 & 4 & 6 & G15xU32 & 6 & 9 \\
\hline G4xU18 & 7 & 6 & G15xU33 & 6 & 9 \\
\hline G4xU19 & 1 & 6 & G15xU34 & 5 & 9 \\
\hline G5xU17 & 2 & 6 & G15xU41 & 3 & 9 \\
\hline G6xU1 & 5 & 6 & G16xU34 & 8 & 9 \\
\hline G6xU8 & 2 & 6 & G16xU35 & 5 & 9 \\
\hline G6xU9 & 1 & 8 & G16xU43 & 1 & 9 \\
\hline G6xU13 & 1 & 8 & G17xU30 & 2 & 9 \\
\hline G6xU14 & 2 & 6 & G17xU33 & 9 & 9 \\
\hline G6xU16 & 1 & 6 & G17xU34 & 7 & 9 \\
\hline G6xU17 & 1 & 6 & G17xU35 & 7 & 9 \\
\hline G6xU18 & 2 & 6 & G17xU36 & 7 & 9 \\
\hline G6xU27 & 5 & 6 & G17xU39 & 7 & 9 \\
\hline G7xU5 & 4 & 6 & G29xU31 & 1 & 9 \\
\hline G7xU8 & 7 & 6 & G31xU36 & 9 & 9 \\
\hline G7xU10 & 1 & 8 & G3xU28 & 1 & 9 \\
\hline G7xU13 & 3 & 6 & G3xU29 & 18 & 9 \\
\hline G7xU18 & 2 & 8 & G3xU32 & 1 & 9 \\
\hline G7xU19 & 3 & 6 & G3xU35 & 9 & 9 \\
\hline G7xU20 & 1 & 6 & G3xU36 & 13 & 9 \\
\hline G7xU21 & 1 & 8 & G3xU37 & 9 & 9 \\
\hline G7xU22 & 1 & 8 & G3xU40 & 9 & 9 \\
\hline G7xU23 & 1 & 8 & G3xU41 & 5 & 9 \\
\hline G8xU13 & 1 & 6 & G3xU43 & 11 & 9 \\
\hline G8xU17 & 5 & 6 & G7xU28 & 4 & 9 \\
\hline G10xU3 & 2 & 8 & G7xU29 & 3 & 9 \\
\hline G10xU6 & 2 & 6 & G7xU40 & 5 & 9 \\
\hline G10xU21 & 1 & 8 & G7xU42 & 2 & 9 \\
\hline G10xU26 & 1 & 6 & G7xU44 & 1 & 9 \\
\hline G11xU6 & 1 & 6 & G8xU28 & 2 & 9 \\
\hline G13xU3 & 1 & 6 & G8xU30 & 4 & 9 \\
\hline
\end{tabular}


G13xU8

G14xU6

G14xU14

G14xU15

G15xU8

G15xU9

G16xU14

G18xU16

G19xU6

G20xU14

G21xU14

G21xU15

G21xU16

G21xU18

G23xU2

G23xU13

G23xU17

G23xU18

G24xU18

G25xU14

G28xU13

G28xU19

G29xU2

G30xU8

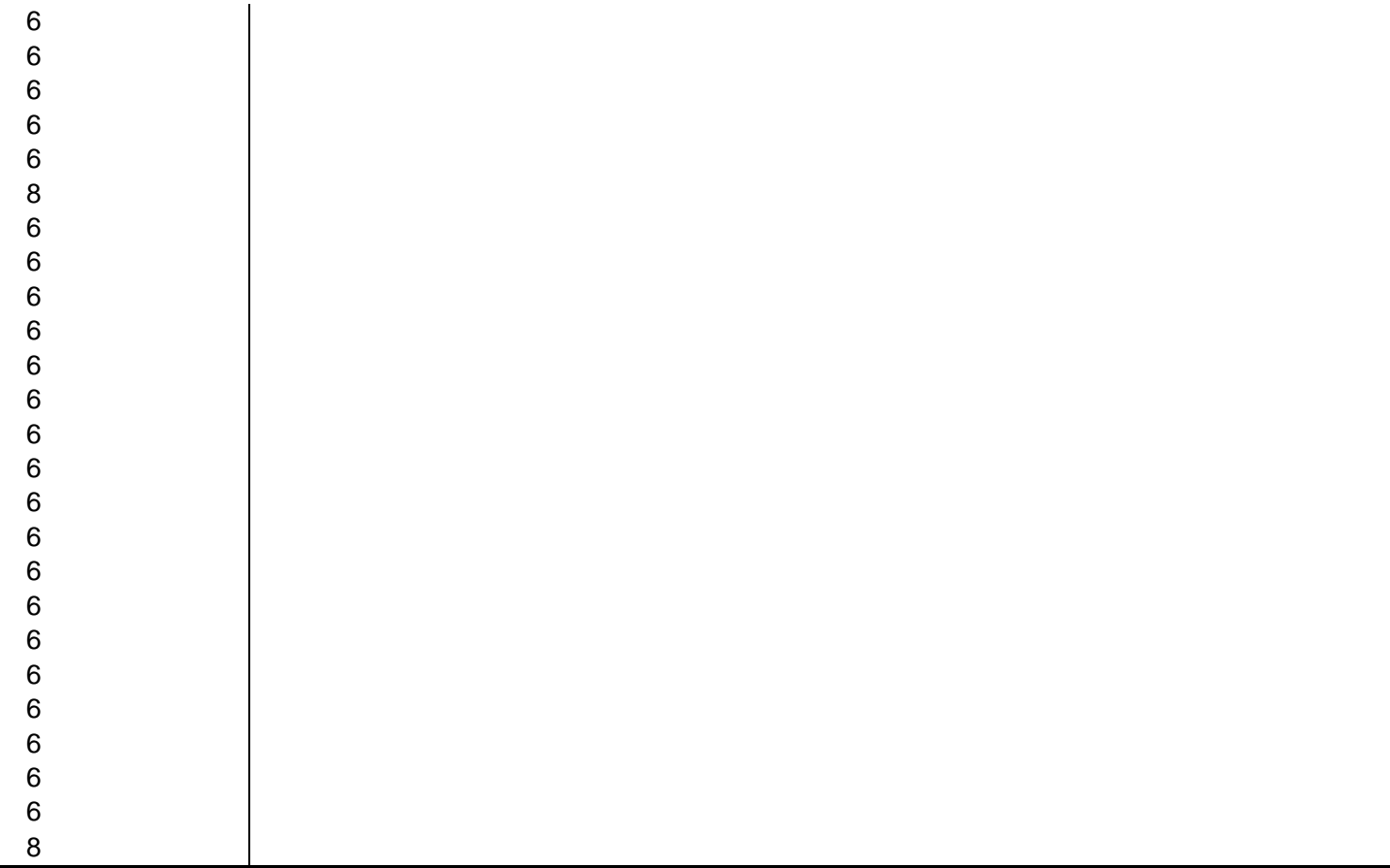


3900 individuals). Between 90 and 180 ramets were produced from each ortet and were established in a series of clonal trials at 9 sites.

In order to link the trials and to calculate realised gains, five common commercial controls were established in all the trials namely:

- One GU current commercial clone

- One E. grandis x E. camaldulensis (GC) current commercial clone

- Two E. grandis post commercial clones

- Improved E. grandis seedlings

The two current commercial hybrid clones are those that were planted commercially at the time when the trials were established. The two E. grandis post commercial clones are those that were planted commercially in Zululand in the early 1990's, and the $E$. grandis seedling control is a third generation bulk seedlot.

\section{Trial establishment and measurements}

The trial sites generally have deep sandy soils and have mean annual temperatures (MAT) of $21^{\circ} \mathrm{C}-21.9^{\circ} \mathrm{C}$ (Table 2). Mean annual precipitation (MAP) range between $862 \mathrm{~mm}$ - $1524 \mathrm{~mm}$. Three GU clonal trial series (IC358A-F, IC361A-F and IC365AH) were established with ramets that were derived from the GU progeny trials and two trial series (IC363A-I and IC365A-H) with ramets that were derived from the HSSB. One clonal trial series (IC365A-H) consists of ramets from both strategies. Between six and nine clonal trials were established for each series. Each trial was planted in a randomized complete block (RCB) design. The clones were planted in single tree plots and replicated (reps) between 15 and 20 times across each site. Spacing was $3 \mathrm{~m} \times 2 \mathrm{~m}$ in all trials. Growth traits namely: height (in metres) and diameter at $1.3 \mathrm{~m},(\mathrm{DBH}$, in centimetres) were taken at four and seven years. Tree 
Table 2: Site and trial information of E. grandis x E. urophylla hybrid clonal trials established with clonal material derived

from the conventional and/or the accelerated hybrid breeding strategy.

\begin{tabular}{|c|c|c|c|c|c|c|c|c|c|}
\hline \multicolumn{10}{|c|}{ IC358 Clonal trial series (Conventional hybrid breeding strategy) } \\
\hline Trial & IC358A & IC358B & IC358C & IC358D & IC358E & IC358F & & & \\
\hline Longitude & $32^{\circ} 06^{\prime} \mathrm{E}$ & $32^{\circ} 03^{\prime} \mathrm{E}$ & $31^{\circ} 42^{\prime} \mathrm{E}$ & $31^{\circ} 43^{\prime} \mathrm{E}$ & $31^{\circ} 53^{\prime} \mathrm{E}$ & $31^{\circ} 50^{\prime} \mathrm{E}$ & & & \\
\hline Latitude & $28^{\circ} 31^{\prime} \mathrm{S}$ & $28^{\circ} 37^{\prime} \mathrm{S}$ & $28^{\circ} 59^{\prime} \mathrm{S}$ & $28^{\circ} 59^{\prime} \mathrm{S}$ & $28^{\circ} 52^{\prime} \mathrm{S}$ & $28^{\circ} 53^{\prime} \mathrm{S}$ & & & \\
\hline M.A.P. (mm) & $1084 \mathrm{~mm}$ & $1051 \mathrm{~mm}$ & $1293 \mathrm{~mm}$ & $1295 \mathrm{~mm}$ & $1379 \mathrm{~mm}$ & $1476 \mathrm{~mm}$ & & & \\
\hline M.A.T. $\left({ }^{\circ} \mathrm{C}\right)$ & $21.6^{\circ} \mathrm{C}$ & $21.6^{\circ} \mathrm{C}$ & $21.1^{\circ} \mathrm{C}$ & $21.1^{\circ} \mathrm{C}$ & $21.3^{\circ} \mathrm{C}$ & $21.1^{\circ} \mathrm{C}$ & & & \\
\hline Altitude (m) & $55 \mathrm{~m}$ & $63 \mathrm{~m}$ & $24 \mathrm{~m}$ & $47 \mathrm{~m}$ & $63 \mathrm{~m}$ & $95 \mathrm{~m}$ & & & \\
\hline Soil type & Kd2000 & FERNWOOD1210 & HUTTON 27 & HUTTON 26 & HUTTON 2200 & HUTTON 2200 & & & \\
\hline E.R.D. (m) & $1-1.4 m$ & 1.51 & 1.21 & 1.21 & 1.51 & 1.51 & & & \\
\hline Planting date & $2005 / 04 / 29$ & $2005 / 05 / 09$ & $2005 / 06 / 17$ & $2005 / 08 / 24$ & $2005 / 06 / 13$ & $2005 / 07 / 05$ & & & \\
\hline Fertiliser & $\begin{array}{l}\text { DAP @ } \\
60 \mathrm{~g} / \text { tree }\end{array}$ & DAP @ 60g/tree & $\begin{array}{l}\text { DAP @ } \\
60 \mathrm{~g} / \text { tree }\end{array}$ & DAP @ 60g/tree & DAP @ 60g/tree & DAP@60g/tree & & & \\
\hline No. of reps & 20 & 20 & 20 & 20 & 20 & 20 & & & \\
\hline No. of clones & 68 & 68 & 68 & 68 & 68 & 68 & & & \\
\hline \multicolumn{10}{|c|}{ IC361 Clonal trial series (Conventional hybrid breeding strategy) } \\
\hline Trial & IC361A & IC361B & IC361C & IC361D & IC361E & IC361F & & & \\
\hline Longitude & $32^{\circ} 12^{\prime} \mathrm{E}$ & $32^{\circ} 08^{\prime} \mathrm{E}$ & $31^{\circ} 58^{\prime} \mathrm{E}$ & $31^{\circ} 49^{\prime} \mathrm{E}$ & $31^{\circ} 41^{\prime} \mathrm{E}$ & $31^{\circ} 42^{\prime} \mathrm{E}$ & & & \\
\hline Latitude & $28^{\circ} 36^{\prime} \mathrm{S}$ & $28^{\circ} 39^{\prime} \mathrm{S}$ & $28^{\circ} 44^{\prime} \mathrm{S}$ & $28^{\circ} 54^{\prime} \mathrm{S}$ & $29^{\circ} 00^{\prime} \mathrm{S}$ & $28^{\circ} 59^{\prime} \mathrm{S}$ & & & \\
\hline M.A.P. $(\mathrm{mm})$ & 1201 & 1116 & 1198 & 1486 & 1273 & 1259 & & & \\
\hline M.A.T. $\left({ }^{\circ} \mathbf{C}\right)$ & 21.6 & 21.5 & 21.3 & 21.1 & 21 & 21.1 & & & \\
\hline Altitude (m) & 55 & 71 & 76 & 79 & 63 & 47 & & & \\
\hline Soil type & $\begin{array}{c}\text { FERNWOOD } \\
1110\end{array}$ & $\begin{array}{c}\text { VILAFONTES } \\
2110\end{array}$ & HUTTON 26 & HUTTON 2200 & HUTTON 26 & Fw32 + We13 & & & \\
\hline E.R.D. (m) & 1.51 & 1.51 & 1.21 & 1.51 & 1.51 & $0.5-0.8$ & & & \\
\hline Planting date & $2006 / 08 / 23$ & $2006 / 09 / 27$ & $2006 / 09 / 15$ & $2006 / 10 / 26$ & $2006 / 08 / 17$ & $2006 / 08 / 18$ & & & \\
\hline Fertiliser & $\begin{array}{l}\text { DAP @ } \\
\text { 60g/tree }\end{array}$ & DAP @ 60g/tree & $\begin{array}{l}\text { DAP @ } \\
\text { 60g/tree }\end{array}$ & DAP@60g/tree & DAP @ 60g/tree & DAP @ 60g/tree & & & \\
\hline No. of reps & 20 & 20 & 20 & 20 & 20 & 20 & & & \\
\hline No. of clones & 85 & 85 & 85 & 85 & 85 & 85 & & & \\
\hline \multicolumn{10}{|c|}{ IC363 Clonal trial series (Accelerated hybrid breeding strategy) } \\
\hline Trial & IC363A & IC363B & IC363C & IC363D & IC363E & IC363F & IC363G & IC363H & IC363I \\
\hline Longitude & $31^{\circ} 40^{\prime} \mathrm{E}$ & $31^{\circ} 44^{\prime} \mathrm{E}$ & $32^{\circ} 12^{\prime} \mathrm{E}$ & $32^{\circ} 22^{\prime} \mathrm{E}$ & $32^{\circ} 03^{\prime} \mathrm{E}$ & $31^{\circ} 49^{\prime} \mathrm{E}$ & $32^{\circ} 25^{\prime} \mathrm{E}$ & $32^{\circ} 11^{\prime} \mathrm{E}$ & $31^{\circ} 52^{\prime} \mathrm{E}$ \\
\hline Latitude & $29^{\circ} 02^{\prime} \mathrm{S}$ & $28^{\circ} 59^{\prime} \mathrm{S}$ & $28^{\circ} 25^{\prime} \mathrm{S}$ & $28^{\circ} 13^{\prime} \mathrm{S}$ & $28^{\circ} 39^{\prime} \mathrm{S}$ & $28^{\circ} 54^{\prime} \mathrm{S}$ & $28^{\circ} 07^{\prime} \mathrm{S}$ & $28^{\circ} 37^{\prime} \mathrm{S}$ & $28^{\circ} 53^{\prime} \mathrm{S}$ \\
\hline M.A.P. $(\mathrm{mm})$ & 1247 & 1291 & 881 & 999 & 1058 & 1467 & 862 & 1211 & 1427 \\
\hline M.A.T. $\left({ }^{\circ} \mathrm{C}\right)$ & 21.0 & 21.2 & 21.9 & 21.8 & 21.7 & 21.2 & 21.9 & 21.6 & 21.3 \\
\hline Altitude (m) & 66 & 16 & 57 & 47 & 39 & 63 & 35 & 60 & 32 \\
\hline Soil tyne & HUTTON & FFBNWOOR 11 & FERNWOOD & FERNWOOD & FERNWOOD & FERNWOOD 1210 & LONGLANDS & FERNWOOD & KROONSTAD \\
\hline Soll type & 2200 & FERINVVOUD II & 11 & 1110 & 1210 & FERINVVOUD ILIO & 1000 & 1210 & 1000 \\
\hline E.R.D. (m) & 1.51 & 1.2 & 1.2 & 1.51 & 1.51 & 1.51 & 0.8 & 1.51 & 0.9 \\
\hline Planting date & $2008 / 03 / 27$ & $2008 / 05 / 27$ & $2008 / 06 / 26$ & $2008 / 08 / 14$ & $2008 / 09 / 05$ & 2008/10/01 & $2008 / 10 / 22$ & $2008 / 10 / 21$ & 2008/10/22 \\
\hline Fertiliser & LAN (28) & LAN (28) & LAN (28) & LAN (28) & LAN (28) & LAN (28) & LAN (28) & LAN (28) & LAN (28) \\
\hline
\end{tabular}




\begin{tabular}{|c|c|c|c|c|c|c|c|c|c|}
\hline $\begin{array}{l}\text { No. of reps } \\
\text { No. of clones }\end{array}$ & $\begin{array}{c}15 \\
115 \\
\end{array}$ & $\begin{array}{c}15 \\
115 \\
\end{array}$ & $\begin{array}{c}15 \\
115 \\
\end{array}$ & $\begin{array}{c}15 \\
115 \\
\end{array}$ & $\begin{array}{c}15 \\
115 \\
\end{array}$ & $\begin{array}{c}15 \\
115 \\
\end{array}$ & $\begin{array}{c}15 \\
115 \\
\end{array}$ & $\begin{array}{c}15 \\
115 \\
\end{array}$ & $\begin{array}{c}15 \\
115 \\
\end{array}$ \\
\hline \multicolumn{10}{|c|}{ IC365 Clonal trial series (Conventional and Accelerated hybrid breeding strategies) } \\
\hline Trial & IC365A & IC365B & IC365C & IC365D & IC365E & IC365F & IC365G & $\mathrm{IC} 365 \mathrm{H}$ & \\
\hline Longitude & $32^{\circ} 09^{\prime} \mathrm{E}$ & $32^{\circ} 08^{\prime} \mathrm{E}$ & $32^{\circ} 18^{\prime} \mathrm{E}$ & $31^{\circ} 50^{\prime} \mathrm{E}$ & $31^{\circ} 43^{\prime} \mathrm{E}$ & $31^{\circ} 52^{\prime} \mathrm{E}$ & $31^{\circ} 09^{\prime} \mathrm{E}$ & $31^{\circ} 15^{\prime} \mathrm{E}$ & \\
\hline Latitude & $28^{\circ} 30^{\prime} \mathrm{S}$ & $28^{\circ} 33^{\prime} \mathrm{S}$ & $28^{\circ} 18^{\prime} \mathrm{S}$ & $28^{\circ} 53^{\prime} \mathrm{S}$ & $28^{\circ} 58^{\prime} \mathrm{S}$ & $28^{\circ} 51^{\prime} \mathrm{S}$ & $28^{\circ} 40^{\prime} \mathrm{S}$ & $28^{\circ} 21^{\prime} S$ & \\
\hline M.A.P. $(\mathrm{mm})$ & 917 & 1008 & 1029 & 1524 & 1266 & 1370 & 1471 & 1038 & \\
\hline M.A.T. $\left({ }^{\circ} \mathrm{C}\right)$ & 21.8 & 21.6 & 21 & 21.5 & 21.1 & 21.5 & 21.5 & 21.9 & \\
\hline Altitude (m) & 51 & 71 & 55 & 47 & 47 & 95 & & & \\
\hline Soil type & FW1110 & FW1210 & FW1110 & FW1210 & Ka10 & Hu2100 & Vf2110 & Fw1110 & \\
\hline E.R.D. (m) & 151 & 151 & 151 & 151 & 50 & 151 & 151 & 151 & \\
\hline Planting date & $2009 / 05 / 30$ & $2009 / 06 / 18$ & $2009 / 06 / 03$ & $2009 / 06 / 30$ & $2009 / 07 / 22$ & 2009/09/09 & $2009 / 09 / 21$ & $2009 / 09 / 22$ & \\
\hline Fertiliser & LAN (28) & LAN (28) & LAN (28) & LAN (28) & LAN (28) & LAN (28) & LAN (28) & LAN (28) & \\
\hline No. of reps & 15 & 15 & 15 & 15 & 15 & 15 & 15 & 15 & \\
\hline No. of clones & 134 & 134 & 134 & 134 & 134 & 134 & 134 & 134 & \\
\hline
\end{tabular}


volume was calculated using the following equation as described by Max and Burkhart (1976):

Volume $=\left(\frac{\pi}{40000}\right) * \mathrm{k}^{*} D B H^{2 *} \mathrm{HT}$

Where,

$\mathrm{k}=\left(\frac{\beta_{1}}{3}\right)+\left(\frac{\beta_{0}}{2}\right)-\left(\beta_{0}+\beta_{1}\right)+\left(\frac{\beta_{2}}{3}\right)^{*} a_{1}{ }^{3}+\left(\frac{\beta_{3}}{3}\right)^{*} a_{2}{ }^{3}$

Functions used to calculate $\mathrm{k}$ were developed internally by Mondi Limited (Kotze and Fletcher, unpublished data).

A detailed description of each trial site is presented in Table 2.

\section{Statistical analysis}

Standardisation of data

The standardisation of data prior to analysis of variances, variance component analysis, or multi-site mixed model analysis is important for three reasons: (1) To homogenized variances that were used together; (2) To eliminate statistically significant interaction for genotype $\mathrm{x}$ environment interaction due to scale effects; and (3) To facilitate bias-free back transformations to predict genetic gains in the units of measure in various environments (Hill 1984; Visscher et al. 1991; Jarvis et al. 1995; White et al. 2007). The standardisation for the analysis of this paper was performed as described by Hodge and Dvorak (2012). PROC STANDARD in SAS (SAS Institute 2002) was used to standardized phenotypic observations in each replication to a mean $=100$. The population mean for the growth trait can therefore be interpreted as $100 \%$, and the associated variances and SD are the same size relative to mean as in the raw data. All variance components 
can thus be directly interpreted as percentage gain (above or below 100\%) without back-transformation or rescaling.

Analysis of the E. grandis $x$ E. urophylla clonal populations

The statistical model used was as follows:

$y_{i j k l m n}=\mu+S_{i}+R_{j(i)}+f_{k}+m_{l}+f m_{k l}+\mathrm{c}_{\mathrm{m}(\mathrm{kl})}+e_{i j k l m n}$

Where,

$y_{i j k l m n}=$ the $n^{\text {th }}$ observation of the $j^{\text {th }}$ replication for the $k^{\text {th }}$ family for the $m^{\text {th }}$ clone at the $i^{\text {th }}$ site;

$\mu \quad=$ overall mean;

$S_{i} \quad=$ fixed effect of the $i^{\text {th }}$ site;

$R_{j(i)} \quad=$ fixed effect of the $j^{\text {th }}$ replication within the $i^{\text {th }}$ site;

$f_{k}$ or $m_{l} \quad=$ the random general hybridising ability (GHA) effect for the $k^{\text {th }}$ female or the ${ }^{\text {th }}$ male;

$\mathrm{fm}_{k l} \quad=$ random specific hybridising ability (SHA) or full-sib hybrid family effect of the $k^{\text {th }}$ and $I^{\text {th }}$ parents;

$c_{m(k l)} \quad=$ random effect of the $m^{\text {th }}$ clone within the full-sib hybrid family of the $k^{\text {th }}$ and Ith $^{\text {th }}$ parents ;

$e_{i j k l m} \quad=$ random within plot error term;

The origin of clonal material; i.e. either from the GU progeny trials for the CHBS, or from the HSSB for the AHBS; was included in the model when a combined analysis of the two clonal populations was conducted. All effects, except the overall mean, site and replication effect, were assumed to be random and independently distributed. PROC MIXED (SAS Institute 2002) in SAS was used to estimate 
variance components and to obtain best linear unbiased predictions (BLUP) of random genetic effects (GHA, SHA and clone) simultaneously. The relationship between variance components and the quantitative genetic model was used to estimate the additive and dominance variance (Falconer 1981), with the assumptions that the inbreeding coefficient of the parents was zero and that epistatic effects are negligible.

$\hat{\sigma}_{\mathrm{f}}^{2}=$ variance due to female (E. grandis) effect,

$\hat{\sigma}_{\mathrm{Af}}^{2}=4 \hat{\sigma}_{\mathrm{f}}^{2}$ is the additive variance due to the female effect,

$\hat{\sigma}_{\mathrm{m}}^{2}=$ variance due to male (E. urophylla) effect,

$\hat{\sigma}_{\mathrm{Am}}^{2}=4 \hat{\sigma}_{\mathrm{m}}^{2}$ is the additive variance due to the male effect,

$\hat{\sigma}_{\mathrm{A}}^{2}=1 / 2\left(\hat{\sigma}_{\mathrm{Af}}^{2}+\hat{\sigma}_{\mathrm{Am}}^{2}\right)$ is the additive variance combining the female and male effect,

$\hat{\sigma}_{\mathrm{fm}}^{2}=$ variance due to full-sib hybrid family effect,

$\hat{\sigma}_{\mathrm{D}}^{2}=4 \hat{\sigma}_{\mathrm{fm}}^{2}$ is the dominance variance,

$\hat{\sigma}_{\mathrm{c}(\mathrm{fm})}^{2}=$ variance due to clone within full-sib hybrid family effect,

$\hat{\sigma}_{\mathrm{NA}}^{2}=\hat{\sigma}_{\mathrm{D}}^{2}+\hat{\sigma}_{\mathrm{c}(\mathrm{fm})}^{2}$ is the total non-additive genetic variance,

$\hat{\sigma}_{\mathrm{G}}^{2}=\hat{\sigma}_{\mathrm{A}}^{2}+\hat{\sigma}_{\mathrm{NA}}^{2}$ is the total genetic variance,

$\hat{\sigma}_{\text {total }}^{2}=\hat{\sigma}_{\mathrm{G}}^{2}+\hat{\sigma}_{\mathrm{e}}^{2}$ is the total phenotypic variance.

Heritabilities were estimated as:

$h_{\mathrm{f}}^{2}=\frac{\widehat{\sigma}_{\mathrm{Af}}^{2}}{\widehat{\sigma}_{\text {total }}^{2}}$ is the narrow-sense heritability for the female half sibs,

$h_{\mathrm{m}}^{2}=\frac{\widehat{\sigma}_{\mathrm{Am}}^{2}}{\widehat{\sigma}_{\text {total }}^{2}}$ is the narrow-sense heritability for the male half sibs,

$h_{\mathrm{i}}^{2}=\frac{\widehat{\sigma}_{\mathrm{A}}^{2}}{\widehat{\sigma}_{\text {total }}^{2}}$ is the narrow-sense heritability for the combined female and male hybrid parents,

$d^{2}=\frac{\widehat{\sigma}_{\mathrm{D}}^{2}}{\widehat{\sigma}_{\text {total }}^{2}}$ is the ratio of dominance variance to total individual phenotypic variance, 
$c^{2}=\frac{\widehat{\sigma}_{\mathrm{c}(\mathrm{fm})}^{2}}{\widehat{\sigma}_{\text {total }}^{2}}$ is the ration of clone within full-sib hybrid family variance to total individual phenotypic variance,

$H_{\mathrm{i}}^{2}=\frac{\widehat{\sigma}_{\mathrm{G}}^{2}}{\widehat{\sigma}_{\text {total }}^{2}}$ is the broad-sense heritability on an individual basis,

Standard errors of heritabilities were calculated by Dickerson's approximation (Dickerson 1969).

The above mentioned analysis was first conducted separately for the two clonal populations of the CHBS and the AHBS in order to estimate genetic parameters and realised genetic gains of the different strategies. The realised genetic gain for each clone was calculated by adding the BLUP estimates of the full-sib hybrid family and the clone within the full-sib hybrid family together. An analysis combining the clonal populations of the two strategies was then performed to estimate the overall genetic parameters of GU clones in Zululand.

\section{Results}

Means, variance component and genetic parameters of two $E$. grandis $x E$. urophylla clonal populations derived from a conventional and accelerated hybrid breeding strategy.

Mean $\mathrm{DBH}$, height, volume per tree and survival for the CHBS and AHBS clonal populations are presented in Table 3. Means were calculated using the pooled data for each of the clonal populations and before the data was standardised. Mean tree volume was slightly higher for the AHBS clonal population $\left(0.1029 \mathrm{~m}^{3}\right)$ than for the CHBS clonal population $\left(0.1009 \mathrm{~m}^{3}\right)$ (Table 3$)$, but not significant $(p<0.462)$ as 
Table 3: Means and ranges for growth traits of two E. grandis x E. urophylla clonal populations derived from a conventional and an accelerated hybrid breeding strategy.

\begin{tabular}{|c|c|c|c|}
\hline & & Conventional & Accelerated \\
\hline \multirow{4}{*}{$\mathrm{DBH}$} & $\mathrm{N}$ & 18000 & 24120 \\
\hline & Mean & 13.3 & 13.2 \\
\hline & Standard deviation & 2.8 & 3.1 \\
\hline & Range & $5.1-24.7$ & $5.0-24.6$ \\
\hline \multirow{3}{*}{ Height } & Mean & 16.5 & 16.5 \\
\hline & Standard deviation & 2.7 & 2.6 \\
\hline & Range & $7.7-26.0$ & $9.8-25.9$ \\
\hline \multirow{3}{*}{ Volume } & Mean & 0.1009 & 0.1029 \\
\hline & Standard deviation & 0.0538 & 0.0605 \\
\hline & Range & $0.0073-0.49998$ & $0.0077-0.4938$ \\
\hline \multirow{2}{*}{ Survival } & Mean & 88.5 & 86.1 \\
\hline & Standard deviation & 31.9 & 34.6 \\
\hline
\end{tabular}


indicated in Table 4. The overall survival was also similar for the CHBS clonal population (88.5\%) and the AHBS clonal populations (86.1\%) (Table 3).

The E. grandis (female) and E. urophylla (male) effects were not significant for volume, regardless of the breeding strategy followed (Table 4). This resulted in additive genetic variation $\left(\hat{\sigma}_{\mathrm{A}}^{2}=61.44\right)$ only explaining $9.6 \%$ of the total genetic variance $\left(\hat{\sigma}_{\mathrm{G}}^{2}=638.46\right)$ when all the data was combined (Table 5). A similar trend was detected for the CHBS and AHBS clonal populations where additive genetic variance explained $29.2 \%(117.8 / 402.96)$ and $11.8 \%(95.8 / 810.91)$ of the total genetic variance respectively. In all the analysis, E. urophylla parents contributed more to the additive genetic variation than the $E$. grandis parents. The $h_{\mathrm{m}}^{2}$ was 0.07 for the CHBS clonal population, 0.08 for the AHBS clonal population and 0.05 for the combined clonal populations, whereas $h_{\mathrm{f}}^{2}$ was $0.06,0.00$ and 0.01 respectively.

With regards to non-additive genetic effects, the clone within family effect was highly significant $(p<0.001)$ for the CHBS, AHBS and combined clonal populations (Table 4). The full-sib hybrid family effect was significant $(p<0.05)$ for the AHBS and combined clonal population, but not for the CHBS clonal population. Non-additive genetic variation $\left(\hat{\sigma}_{\mathrm{NA}}^{2}=577.02\right)$ explained $90.3 \%$ of the total genetic variation $\left(\hat{\sigma}_{\mathrm{G}}^{2}=638.46\right)$ of the combined clonal population (Table 5). Similar values were obtained for the CHBS clonal population (71\%) and the AHBS population (88\%). Fifty six percent of the non-additive variation $\left(\hat{\sigma}_{\mathrm{NA}}^{2}=577.02\right)$ could be explained by the dominance variance $\left(\hat{\sigma}_{D}^{2}=323.24\right)$ for the combined clonal population. The rest of the non-additive genetic variation was explained by the variation among clones within a full-sib hybrid family $\left(\hat{\sigma}_{\mathrm{c}(\mathrm{fm})}^{2}=253.78\right)$. A discrepancy was noted between the CHBS and AHBS clonal populations where dominance variance explained $21 \%$ and $63 \%$ of the non-additive genetic variation respectively. The main cause of the relatively low 
Table 4: Variance components for volume of the random effects of two E. grandis $\times$ E. urophylla clonal populations derived from a conventional and an accelerated hybrid breeding strategy.

\begin{tabular}{|c|c|c|c|c|c|c|}
\hline & & Effect & Estimate & SE & ZValue & ProbZ \\
\hline \multirow{13}{*}{ 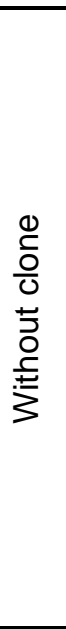 } & \multirow{4}{*}{ Conventional } & female & 29.89 & 28.23 & 1.06 & 0.145 \\
\hline & & male & 33.76 & 25.50 & 1.32 & 0.093 \\
\hline & & full sib hybrid families & 132.25 & 35.70 & 3.70 & $<0.001$ \\
\hline & & error & 1614.63 & 18.34 & 88.06 & $<0.001$ \\
\hline & \multirow{4}{*}{ Accelerated } & female & 0 & & & \\
\hline & & male & 68.19 & 60.48 & 1.13 & 0.129 \\
\hline & & full sib hybrid families & 163.00 & 54.62 & 2.98 & $<0.001$ \\
\hline & & error & 1613.05 & 15.93 & 101.23 & $<0.001$ \\
\hline & \multirow{5}{*}{ All } & strategy & 0.00 &. &. &. \\
\hline & & female & 11.45 & 18.75 & 0.61 & 0.271 \\
\hline & & male & 30.56 & 23.54 & 1.30 & 0.097 \\
\hline & & full sib hybrid families & 164.38 & 34.37 & 4.78 & $<0.001$ \\
\hline & & error & 1615.99 & 12.02 & 134.39 & $<0.001$ \\
\hline \multirow{16}{*}{ 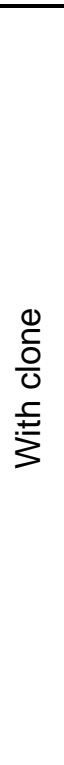 } & \multirow{5}{*}{ Conventional } & female & 28.49 & 29.80 & 0.96 & 0.169 \\
\hline & & male & 30.41 & 25.48 & 1.20 & 0.116 \\
\hline & & full sib hybrid families & 15.08 & 33.72 & 0.45 & 0.327 \\
\hline & & clone(fam) & 224.84 & 36.20 & 6.76 & $<0.001$ \\
\hline & & error & 1464.49 & 16.67 & 87.82 & $<0.001$ \\
\hline & \multirow{5}{*}{ Accelerated } & female & 0.00 & 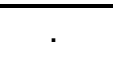 & 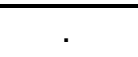 & \\
\hline & & male & 47.90 & 54.58 & 0.88 & 0.19 \\
\hline & & full sib hybrid families & 113.40 & 54.97 & 2.60 & 0.019 \\
\hline & & clone (fam) & 261.51 & 30.22 & 8.65 & $<0.001$ \\
\hline & & error & 1402.99 & 13.91 & 100.82 & $<0.001$ \\
\hline & \multirow{6}{*}{ All } & strategy & 2.24 & 23.57 & 0.10 & 0.462 \\
\hline & & female & 4.17 & 16.08 & 0.26 & 0.397 \\
\hline & & male & 26.55 & 23.50 & 1.13 & 0.129 \\
\hline & & full sib hybrid families & 80.81 & 31.90 & 2.53 & 0.006 \\
\hline & & clone(fam) & 253.78 & 23.11 & 10.98 & $<0.001$ \\
\hline & & error & 1242.83 & 9.58 & 129.69 & $<0.001$ \\
\hline
\end{tabular}


Table 5: Genetic parameters at four years for volume of two E. grandis x E. urophylla clonal populations derived from a conventional and an accelerated breeding strategy.

\begin{tabular}{|c|c|c|c|c|c|c|}
\hline & \multicolumn{2}{|c|}{ Conventional } & \multicolumn{2}{|c|}{ Accelerated } & \multicolumn{2}{|c|}{ All } \\
\hline & with clone & without clone & with clone & without clone & with clone & without clone \\
\hline \multicolumn{7}{|c|}{ Female (E. grandis) } \\
\hline$\hat{\sigma}_{f}^{2}$ & $28.49 \pm 27.51$ & $29.89 \pm 27.06$ & $0 \pm 0$ & $0 \pm 0$ & $4.17 \pm 16.21$ & $11.45 \pm 18.97$ \\
\hline$\hat{\sigma}_{\mathrm{Af}}^{2}$ & $113.96 \pm 110.05$ & $119.56 \pm 108.26$ & $0 \pm 0$ & $0 \pm 0$ & $16.68 \pm 64.75$ & $45.80 \pm 75.89$ \\
\hline$h_{\mathrm{f}}^{2}$ & $0.06 \pm 0.07$ & $0.05 \pm 0.04$ & $0 \pm 0$ & $0 \pm 0$ & $0.01 \pm 0.04$ & $0.02 \pm 0.04$ \\
\hline \multicolumn{7}{|c|}{ Male (E. urophylla) } \\
\hline$\hat{\sigma}_{\mathrm{m}}^{2}$ & $30.41 \pm 23.75$ & $33.76 \pm 23.49$ & $47.90 \pm 54.31$ & $68.19 \pm 57.89$ & $26.55 \pm 23.72$ & $30.56 \pm 22.92$ \\
\hline$\hat{\sigma}_{\mathrm{Am}}^{2}$ & $121.64 \pm 94.99$ & $135.04 \pm 93.97$ & $191.60 \pm 217.22$ & $272.76 \pm 231.52$ & $106.20 \pm 94.91$ & $122.54 \pm 91.74$ \\
\hline$h_{\mathrm{m}}^{2}$ & $0.07 \pm 0.06$ & $0.06 \pm 0.04$ & $0.08 \pm 0.10$ & $0.11 \pm 0.11$ & $0.05 \pm 0.04$ & $0.05 \pm 0.04$ \\
\hline \multicolumn{7}{|c|}{ Full sib hybrid family } \\
\hline$\hat{\sigma}_{\mathrm{fm}}^{2}$ & $15.08 \pm 31.49$ & $132.25 \pm 33.8$ & $113.40 \pm 54.24$ & $163.00 \pm 50.68$ & $80.81 \pm 31.64$ & $164.38 \pm 34.59$ \\
\hline$\hat{\sigma}_{\mathrm{D}}^{2}$ & $60.32 \pm 125.98$ & $529.00 \pm 135.17$ & $453.60 \pm 216.96$ & $652.00 \pm 202.7$ & $\begin{array}{c}323.24 \pm 126.5 \\
5\end{array}$ & $657.52 \pm 138.33$ \\
\hline$d^{2}$ & $0.03 \pm 0.08$ & $0.23 \pm 0.08$ & $0.20 \pm 0.09$ & $0.27 \pm 0.11$ & $0.16 \pm 0.06$ & $0.28 \pm 0.07$ \\
\hline \multicolumn{7}{|c|}{ Clone(fam) } \\
\hline$\hat{\sigma}_{\mathrm{c}(\mathrm{fm})}^{2}$ & $224.84 \pm 33.71$ & & $261.51 \pm 29.75$ & & $253.78 \pm 22.81$ & \\
\hline$c^{2}$ & $0.12 \pm 0.08$ & & $0.12 \pm 0.07$ & & $0.12 \pm 0.05$ & \\
\hline$\hat{\sigma}_{\mathrm{A}}^{2}$ & 117.8 & 127.3 & 95.80 & 136.38 & 61.44 & 84.17 \\
\hline$\hat{\sigma}_{\mathrm{NA}}^{2}$ & 285.16 & 529 & 715.11 & 652 & 577.02 & 657.52 \\
\hline$\hat{\sigma}_{\mathrm{G}}^{2}$ & 402.96 & 656.3 & 810.91 & 788.38 & 638.46 & 741.69 \\
\hline$H_{\mathrm{i}}^{2}$ & 0.22 & & 0.37 & 0.33 & 0.31 & 0.31 \\
\hline$\hat{\sigma}_{\mathrm{e}}^{2}$ & $1464.49 \pm 15.01$ & $1614.63 \pm 16.72$ & $1402.99 \pm 11.76$ & $1613.05 \pm 14.97$ & $1432.39 \pm 9.58$ & $1615.99 \pm 11.44$ \\
\hline$\hat{\sigma}_{\text {total }}^{2}$ & 1867.45 & 2270.93 & 2213.90 & 2401.43 & 2070.85 & 2357.68 \\
\hline
\end{tabular}


dominance variation present in the CHBS clonal population could be due to the fact that in many cases, only one or two individuals were selected from a specific cross to test as clones. Hence, the data from the CHBS clonal population might be inadequate to partition the non-additive genetic variance into dominance and clone within family variation. In order to try and shed some light onto the nature of nonadditive and additive genetic effects, the random clonal within family effect was dropped from the linear model. It is apparent from Table 4 that when the clone within family effect was dropped from the model, the full-sib hybrid family effect changed from insignificant $(p<0.327)$ to highly significant $(p<0.001)$ for the CHBS clonal population. This resulted in an increase of $d^{2}$ from 0.03 to 0.23 for the CHBS clonal population (Table 5). An increase in $d^{2}$ was also detected for the AHBS clonal population (from 0.20 to 0.27 ) and for the combined clonal population (from 0.16 to 0.28). The $\hat{\sigma}_{\mathrm{A}}^{2}$ however, stayed low for the CHBS, ABHS and combined clonal populations and only explained $11.3 \%(84.17 / 741.69)$ of the total genetic variation of the combined population (Table 5). This is an indication that the effects which the model previously allocated to remaining genetic effects among clones within a family are now mostly being absorbed by the inferred dominance genetic component of variation. This result points to a potential strong confounding effect between dominance and other epistatic terms present in the clone effect. Nevertheless, results from both the CHBS and AHBS hybrid breeding strategies indicated that a breeding strategy to capture non-additive genetic effects will be the most appropriate strategy to follow. The same phenomenon was noted by van den Berg et al. (2016) for the GU seedling population from where the clonal material of the CHBS population was selected from. 


\section{Realised genetic gains of two hybrid breeding strategies}

Best linear unbiased prediction estimates for each full-sib hybrid family and clone within a full-sib hybrid family were directly interpreted as percentage gain due to the way the data was standardised. The realised gain for each clone was calculated by adding the BLUP estimates of the full-sib hybrid family and the clone within that family. In order to quantify the potential gains per unit time for the two strategies, the average gain of the top $5 \%$ of each population was calculated (Table 6). This amounted to a total of 8 clones for the CHBS clonal population with an average gain of $31.3 \%$ over the population mean and $19.4 \%$ gain over the commercial GU clonal control. The top $5 \%$ of the AHBS population equated to 11 clones with an average gain of $41.6 \%$ over the population mean and $28.1 \%$ gain over the commercial GU clonal control. The difference in gains of the top $5 \%$ of two clonal populations was more profound when the time it took to test the material was considered in the calculation. The percentage gain per year was calculated at $3.1 \%$ and $5.5 \%$ over the population mean for the top $5 \%$ of the CHBS and AHBS clonal populations respectively (Figure 2). 
Table 6: Genetic gains of the top $5 \%$ of clones from the conventional and accelerated clonal populations.

\begin{tabular}{|c|c|c|c|c|c|c|}
\hline & \multicolumn{3}{|c|}{ Conventional } & \multicolumn{3}{|c|}{ Accelerated } \\
\hline & $\%$ gain & $\begin{array}{c}\text { Length of cycle } \\
\text { (years) }\end{array}$ & $\begin{array}{c}\% \text { gain per } \\
\text { year }\end{array}$ & $\%$ gain & $\begin{array}{l}\text { Length of cycle } \\
\text { (years) }\end{array}$ & $\begin{array}{c}\% \text { gain per } \\
\text { year }\end{array}$ \\
\hline \% gain over population mean & 31.3 & 10 & 3.1 & 41.6 & 7.5 & 5.5 \\
\hline \% gain over GU clone control & 19.4 & 10 & 1.9 & 28.1 & 7.5 & 3.7 \\
\hline$\%$ gain over E. grandis seedling control & 43.9 & 10 & 4.4 & 51.3 & 7.5 & 6.8 \\
\hline$\%$ gain over GC clone control & 57.7 & 10 & 5.8 & 65.9 & 7.5 & 8.8 \\
\hline$\%$ gain over E. grandis clone 1 control & 57.9 & 10 & 5.8 & 64.9 & 7.5 & 8.7 \\
\hline$\%$ gain over $\mathrm{E}$. grandis clone 2 control & 61.1 & 10 & 6.1 & 68.1 & 7.5 & 9.1 \\
\hline
\end{tabular}


Figure 2: Realised gains of the conventional and accelerated hybrid breeding strategies.

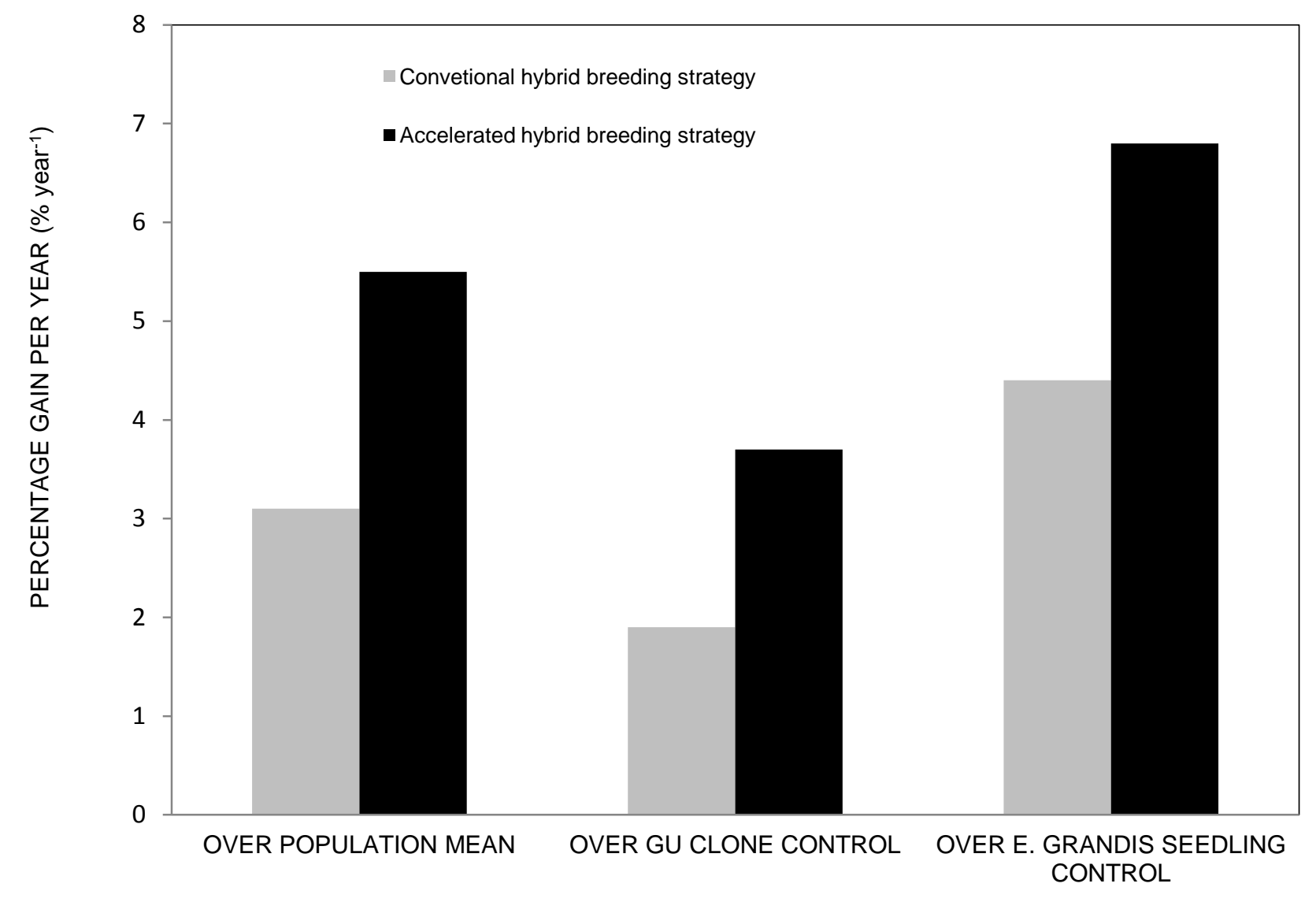




\section{Discussion}

It was evident in our study that the testing of GU seedlings over a shorter time period had a positive impact on volume gains per unit time. The percentage gain (over the GU commercial clonal control) per year was higher for the AHBS (3.7\%) than for the CHBS (1.9\%) (Table 6). In addition, extra costs associated with the CHBS, such as the establishment, maintenance and measurements of GU seedling progeny trials, will also have a negative impact on the cost effectiveness of this strategy.

Another important issue to consider when an improvement strategy is applied to plant or animal species is the proportion of additive variance to the total genetic variance (Lynch and Walsh 1998). The results from our study indicated that additive genetic variation explained minority (between $10 \%$ and $30 \%$ ) of the genetic variation present in GU clonal populations, regardless of the hybrid breeding strategy followed. Although there is little information available on genetic parameters of GU clonal populations, some authors reported the same phenomenon for GU hybrid seedling populations (Rezende and de Resende 2000; Vigneron et al. 2000; Bouvet et al. 2009; Retief and Stanger 2009; Van den Berg et al. 2016). For instance, Retief and Stanger (2009) reported that dominance genetic effects accounted for nearly $60 \%$ of the total genetic variance in a GU hybrid factorial study in Zululand, and Bouvet et al. (2009) reported an average ${ }_{\mathrm{D}}^{2} / \hat{\sigma}_{\mathrm{A}}^{2}$ ratio of 1.2 for a relatively large $\mathrm{GU}$ hybrid seedling population (684 families). In addition, some results on eucalypt pure species populations also indicated a positive $\hat{\sigma}_{\mathrm{D}}^{2} / \hat{\sigma}_{\mathrm{A}}^{2}$ ratio (Van Wyk 1990; Vaillancourt et al. 1995; Hodge et al. 1996; Hardner and Tibbits 1998; Volker et al. 2008). One explanation of the relatively high non-additive variance could be due to the nature of dominance variance. The dominance effect between alleles and their frequency will 
determine the magnitude of the dominance variance (Gallais 1991; Lynch and Walsh 1998). Dominance variance exceeds additive variance in the case of overdominance and/or in the case of total dominance when frequencies of alleles are different when a model of one locus and two alleles are used (Lynch and Walsh 1998). Although the case of overdominance must be considered with caution (Birchle et al. 2006), it may explain some of the relatively high dominance variance present in perennial plants such as Eucalyptus (Bouvet et al. 2009). It must also be borne in mind that the selection process of first selecting elite pure species parents to use for hybrid crossing, followed by the selection of ortets from the hybrid population to test as clones, may influence the additive and non-additive variance estimates of the clonal populations. This effect was evident in our study when a decrease in $h_{\mathrm{i}}^{2}$ from 0.12 to 0.06 was noted when the GU hybrid seedling population (Van den Berg et al. 2016) from where the ortets were selected, was compared to the CHBS clonal population. Nevertheless, our results indicate that following the current selection processes, a breeding strategy to capture non-additive genetic effects in GU hybrids will be the most appropriate strategy to follow. Three strategies that could potentially exploit non-additive variance are reciprocal recurrent selection (RRS) (Comstock et al. 1949), reciprocal recurrent selection with forward selection (RRS-SF; Nikles 1992) and the development and crossing of inbred lines. The implications of these strategies for tree improvement have been discussed by various authors (Vigneron 1991; Nikles 1992; Dungey et al. 2000; Shelbourne 2000; Hettasch et al. 2002). Kerr et al. (2004) did a simulation study comparing RRS, RRS-SF, recurrent selection for general combining ability (RS-GCA; Jenkins 1940) and the hybrid swarm strategy over five cycles of breeding. Results from this study suggest that the RRS-SF strategy yielded the highest genetic gains per year in cases where non-additive 
variance is higher than additive variance and when the pure-hybrid correlations are negative or close to zero. However, majority of the above mentions studies were based on seedling populations, and did not consider the effects of clonal testing. Currently, GU hybrids are commercially deployed as clones and not as seedlings. Hence, a combined strategy to provide a superior GU hybrid seedling source, and to test ramets of selected ortets cost effectively needs to be applied. Based on the results of our study and other authors, a strategy combining RRS-SF and AHBS will most likely result in the most cost effective genetic gains.

\section{Conclusions}

Our study showed that the testing of GU seedlings over a shorter time period had a positive impact on volume gains per unit time when the clonal populations of the conventional and accelerated hybrid breeding strategies were compared. Furthermore, the additional cost savings associated with the AHBS will also help to justify the continuation of this strategy. Overall, both the AHBS and CHBS clonal populations provided similar genetic information. Results indicated that non-additive variance explained the majority ( $88 \%$ and $71 \%)$ of the genetic variation in the AHBS and CHBS GU hybrid clonal sub-populations respectively. It is recommended that a hybrid breeding strategy to capture the non-additive genetic effects should be adopted and combined with a strategy that minimises the time spend on testing GU hybrid material as seedlings.

Although the study has offered an evaluative perspective on Eucalyptus hybrid breeding, information on the economic impact of the two hybrid strategies was 
limited. A future experiment designed to quantify the economic impact associated with cost savings will help to shed light on this discourse.

\section{Acknowledgements}

The authors thank the Mondi Research Team for assistance with trial establishment and measurements. They also thank the Mondi management team for making the data available and for constant support. Funding was provided by Mondi training department. 


\section{References}

Birchle JA, Yao H, Chudalayandi S. 2006. Unraveling the genetic basis of hybrid vigor. Proceedings of National Academy of Science USA 103: 12957-12958.

Bouvet JM, Saya A, Vigneron Ph. 2009. Trends in additive, dominance and environmental effects with age for growth traits in Eucalyptus hybrid populations. Euphytica 165: 35-54.

Comstock R, Robinson H, Harvey P. 1949. A breeding procedure design to make maximum use of both general and specific combining ability. Agon Journal 41: 360-367.

De Assis TF. 2000. Production and use of Eucalyptus hybrids for industrial purposes. In: Dungey $\mathrm{H}$, Dieters $\mathrm{M}$, Nikles $\mathrm{D}$ (eds), Proceedings of the QFRI/CRC-SPF Symposium: Hybrid Breeding and Genetics of Forest Trees, 9-14 April 2000, Noosa, Queensland. Australia: Department of Primary Industries. pp 63-74.

Denison NP, Kietzka JE. 1992. The use and importance of hybrid intensive forestry in South Africa. In: Lambeth C, Dvorak W (eds), Proceedings of the IUFRO Conference: Resolving tropical forest resource concerns through tree improvement, gene conservation and domestication of new species, October 1992, Cali, Colombia. pp 348-358.

Dickerson GE. 1969. Techniques for research in quantitative animal genetics. In:

Techniques and procedures in animal science research. Albany, New York: American Society of Animal Science. pp 36-79.

Dungey HS, Kerr JR, Dieters MJ. 2000. A simulation of the comparative gains from three different hybrid breeding schemes (II) Results. In: Dungey H, Dieters M, Nikles D (eds), Proceedings of the QFRI/CRC-SPF Symposium: Hybrid 
Breeding and Genetics of Forest Trees, 9-14 April 2000, Noosa, Queensland. Australia: Department of Primary Industries. pp 351-356.

Endo M, Lambeth CC. 1992. Promising potential of hybrid, Eucalyptus grandis $x$ Eucalyptus urophylla, over Eucalyptus grandis in Colombia. In: Lambeth C, Devorak W (eds), Proceedings of the IUFRO Conference: Resolving tropical forest resource concerns through tree improvement, gene conservation and domestication of new species, October 1992, Cali, Colombia. pp 366-371.

Falconer DS. 1981. Introduction to quantitative genetics. United Kingdom: Longman Scientific \& Technical

Ferreira M, Santos PET. 1997. Genetic improvement of Eucalyptus in Brazil-brief review and perspectives. In: Proceedings of the IUFRO Conference: sobre Silvicultura e Melhoramento de Eucaliptos, El Salvador, Brazil. pp 14-33.

Gallais A. 1991. Théorie de la selection en amelioration des plantes. Editions Masson, Paris.

Gardner RAW. 2001. Alternative eucalypt species for Zululand: seven year results of site:species interaction trials in the region. Southern African Forestry Journal 190: 79-88.

Griffin AR, Burgess IP, Wolf L. 1988. Patterns of natural and manipulated hybridization in the genus Eucalyptus L'Herit - a review. Australian Journal of Botany 36: 41-66.

Hardner C, Tibbits W. 1998. Inbreeding depression for growth, wood, and fecundity traits in Eucalyptus nitens. Forest Genetics 5: 11-20.

Hettasch MH, Lunt KA, Pierce BT, Snedden CL, Steyn DJ, Venter HM, Verryn SD. 2002. Tree Breeding Course Manual. Pretoria: South Africa. 
Hill WG. 1984. On selection among groups with heterogeneous variance. Animal Production 39: 473-477.

Hodge GR, Volker PW, Potts BM, Owen JV. 1996. A comparison of genetic information from open-pollinated and control-pollinated progeny tests in two eucalypt species. Theoretical and Applied Genetics 92: 53-63.

Hodge GR, Dvorak WS. 2012. Growth potential and genetic parameters of four Mesoamerican pines planted in the Southern Hemisphere. Southern Forests 74(1): 27-49.

Jarvis SF, Borralho NMG, Potts BM. 1995. Implementation of a multivariate BLUP model for genetic evaluation of Eucalyptus globulus in Australia. In: Potts BM, Borralho NMG, Reid JB, Cromer RN, Tibbits WN, Raymond CA (eds), Proceedings of the IUFRO Conference: Eucalyptus plantations: Improving Fibre Yield and Quality, Hobart, Australia. pp 212-216.

Jenkins MT. 1940. The segregation of genes affecting yield of grain in maize. Journal of the American Society of Agronomy 32: 55-63.

Kerr RJ, Dieter MJ, Tier B. 2004. Simulation of the comparative gains from four different hybrid tree breeding strategies. Canadian Journal of Forests Research 34: 209-220.

Lynch M, Walsh B. 1998. Genetics and analysis of quantitative traits. Sunderland: Sinauer Associates.

Max TA, Burkhart HE. 1976. Segmented Polynomial Regression Applied to Taper Equations. Forest Science. Vol. 2. pp 283-289.

Nikles DG. 1992. Hybrids of forest trees: the bases of hybrid superiority and a discussion of breeding methods. In: Lambeth C, Devorak W (eds), Proceedings of the IUFRO Conference: Resolving tropical forest resource concerns through 
tree improvement, gene conservation and domestication of new species, October 1992, Raleigh, USA. North Carolina: North Carolina State University. pp 333-347.

Potts BM, Wiltshire RJE. 1997. Eucalypt genetics and genecology. In: Williams JE, Woinarski JCZ (eds), Eucalypt Ecology: Individuals to Ecosystems. Cambridge: Cambridge University Press. pp 56-91.

Retief ECL, Clarke CRE. 2000. The effect of site potential on eucalypt clonal performancein coastal Zululand, South Africa. In: Proceedings of the IUFRO, Working Party: Forest Genetics for the Next Millennium, Durban, South Africa. pp 192-196.

Retief ECL, Stanger TK. 2009. Genetic parameters of pure and hybrid populations of Eucalyptus grandis and E. urophylla and implications for hybrid breeding strategy. Southern Forests 71(2): 133-140.

Rezende GDSP, de Resende MDV. 2000. Dominance effects in Eucalyptus grandis, Eucalyptus urophylla and Hybrids. In: Dungey H, Dieters M, Nikles D (eds), Proceedings of the QFRI/CRC-SPF Symposium: Hybrid Breeding and Genetics of Forest Trees, 9-14 April 2000, Noosa, Queensland. Australia: Department of Primary Industries. pp 93-100

SAS Institute. 2002. SAS 9.1.3 help and documentation. Cary: SAS Institute.

Shelbourne CJA. 2000. Some insights on hybrids in forest tree improvement. In: Dungey $\mathrm{H}$, Dieters $\mathrm{M}$, Nikles $\mathrm{D}$ (eds), Proceedings of the QFRI/CRC-SPF Symposium: Hybrid Breeding and Genetics of Forest Trees, 9-14 April 2000, Noosa, Queensland. Australia: Department of Primary Industries. pp 53-62. 
Vaillancourt RE, Potts BM, Watson M, Volker PW, Hodge GR, Reid JB, West AK. 1995. Detection and prediction of heterosis in Eucalyptus globulus. Forest Genetics 2: 11-19.

Van Wyk G. 1990. Genetic improvement of timber yield and wood quality in Eucalyptus grandis (Hill) Maiden. Part I. Genetic parameters of growth characteristics. South African Forestry Journal 153: 1-11.

Van den Berg GJ, Verryn SD, Chirwa PW, Van Deventer F. In press. Genetic parameters of interspecific hybrids of Eucalyptus grandis and E. urophylla seedlings and cuttings. Silvae Genetica 64 (5-6): 291-308.

Verryn SD. 2000. Eucalyptus hybrid breeding in South Africa. In: Dungey H, Dieters M, Nikles D (eds), Proceedings of the QFRI/CRC-SPF Symposium: Hybrid Breeding and Genetics of Forest Trees, 9-14 April 2000, Noosa, Queensland. Australia: Department of Primary Industries. pp 191-199.

Vigneron P. 1991. Creation et amelioration de varieties hybrids d'Eucalyptus au Congo. In: Schönau APG (eds), Proceedings of the IUFRO Symposium: Intensive forestry: the role of eucalypts, 2-6 September 1991, Durban, South Africa. Pretoria: Southern African Institute of Forestry. pp 345-360.

Vigneron P, Bouvet JM, Gouma R, Saya A, Gion JM, Verhaegen D. 2000. Eucalypt hybrid breeding in Congo. In: Dungey $H$, Dieters $M$, Nikles D (eds), Proceedings of the QFRI/CRC-SPF Symposium: Hybrid Breeding and Genetics of Forest Trees, 9-14 April 2000, Noosa, Queensland. Australia: Department of Primary Industries. pp 14-26.

Visscher PM, Thompson R, Hill WG. 1991. Estimation of genetic and environmental variances for fat yield in individual herds and an investigation into 
heterogeneity of variance between herds. Livestock Production Science 28: 273-290.

Volker PW, Potts BM, Borralho NMG. 2008. Genetic parameters of intra- and interspecific hybrids of Eucalyptus globulus and E. nitens. Tree Genomics and Genomes 4: 445-460.

White TL, Adams WT, Neale DA. 2007. Forest genetics. Wallingford: CAB International.

Wright JA. 1997. A review of the worldwide activities in tree improvement for Eucalyptus grandis, Eucalyptus urophylla and the hybrid urograndis. In: White T, Huber D, Powell G (eds), Southern forest tree improvement committee. Orlando: Gainesville. pp 96-102.

Zobel B, Talbert J. 1984. Applied Forest Tree Improvement. New York: John Wiley \& Sons. 